\title{
Experiences of medical teachers in flipped learning for medical students: a phenomenological study
}

\author{
Kyung Hye Park', Kwi Hwa Park $^{2}$ and Su Jin Chae ${ }^{3}$ \\ ${ }^{1}$ Department of Medical Education, Yonsei University Wonju College of Medicine, Wonju, ${ }^{2}$ Department of Medical \\ Education, Gachon University College of Medicine, Incheon, and ${ }^{3}$ Department of Medical Humanities \& Social \\ Medicine, Ajou University School of Medicine, Suwon, Korea
}

Purpose: The purpose of this study was to explore the experience of medical teachers in the process of adapting flipped learning method through a phenomenological approach.

Methods: Semi-structured interviews with five medical teachers from two medical colleges and one medical school were conducted in December, 2017. Data analysis was done according to Colaizzi's descriptive phenomenological methodology.

Results: A total of 160 unique significant statements were extracted. These statements generated 17 formulated meanings that were categorized into seven theme clusters and four theme categories. Main themes were: (1) teacher with high levels of passion and motivation; (2) hurdles of flipped learning: students were still passive, struggling in preparing for flipped learning; (3) positive changes from flipped learning: changes to classroom environment and teachers' reflection through experience; and (4) challenges of flipped learning: remaining tasks for teachers, expansion of flipped learning.

Conclusion: Through phenomenological approach, researchers were able to elucidate categories about the experience of medical teachers when attempting flipped learning. Although medical teachers did not have the exact same idea on how flipped learning was conducted and implemented, the perception of flipped learning, or difficulties in class activities, they were still wondering how they could teach students well. This study might draw more attention to flipped learning and stimulate educational and institutional supports to improve teaching and learning in medical schools.

Key Words: Medical students, Medical schools, Medical education, Learning, Qualitative research

\section{Introduction}

Recent trends in medical education have shifted to lecture hall without lectures, emphasizing student-led and student-engaging activities rather than teachercentered lectures in the classroom [1]. Flipped classrooms or flipped learning have gained attention as one of new teaching methods. In flipped learning, a traditional classroom environment is inverted [2]. Pre-class learning materials such as video, audio, text book, and lecture notes are viewed and completed by students before the class. When in class, students are engaged in more student-centered activities while solving problems, collaborating with other students, and applying knowledge. In traditional teaching, most medical teacher's role is to provide information through lectures. However, in a flipped classroom, students, not medical
Received: April 16, 2018 • Revised: May 6, 2018 • Accepted: May 6, 2018

Corresponding Author: Kwi Hwa Park (https://orcid.org/0000-0002-0008-2400)

Department of Medical Education, Gachon University College of Medicine, 38 Dokjeom-ro 3beon-gil, Namdong-gu, Incheon 21565, Korea

Tel: +82.32.458.2635 Fax: +82.32.421.5537 email: ghpark@gachon.ac.kr

Corresponding Author: Su Jin Chae (https://orcid.org/0000-0003-3060-8933)

Department of Medical Humanities \& Social Medicine, Ajou University School of Medicine, 164 World cup-ro, Yeongtong-gu, Suwon 16499, Korea

Tel: +82.31.219.4511 Fax: +82.31.219.4093 email: edujin@ajou.ac.kr
Korean J Med Educ 2018 Jun; 30(2): 91-100

https://doi.org/10.3946/kjme.2018.84

eISSN: 2005-7288

(C) The Korean Society of Medical Education. All rights reserved. This is an open-access article distributed under the terms of the Creative Commons Attribution Non-Commercial License (http:// creativecommons.org/licenses/by-nc/3.0/), which permits unrestricted non-commercial use, distribution, and reproduction in any medium, provided the original work is properly cited. 
teachers, are at the center of learning.

Previous studies have reported on experiences of flipped learning and its effectiveness in medical education. These research studies have found that flipped learning is effective in promoting learning motivation of medical students [3] and improving their academic achievement [4]. However, these studies mainly focused on medical students' experiences. While it is important to investigate how medical students perceive the implementation of a new teaching method [5], it is also important to understand the benefits and obstacles experienced by medical teachers who prepare for the class. The application of new teaching methods is always challenging not only for medical students, but also for medical teachers. With flipped learning, the role of medical teacher must be transformed into facilitating learning of student which is challenging for them [6]. From their flipped learning experiences, they felt that students had improved confidence in their learning. However, they also have obstacles, including a lack of time to prepare for classes, logistics concerns such as room space, and frustration caused by unprepared students [7]. Researches analyzing teacher's experiences in fields such as nursing [7] and science [8] have been published. However, there is little discussion related to flipped classroom in medical education setting.

From the perspective of medical teachers, it is important how they interpret and give meaning to flipped learning that they experience. In this case, phenomenological approach as one of qualitative research methods is often used based on in-depth interviews $[7,8]$. Interests and needs for flipped learning have been increasing in medical education of Korea [9]. Nevertheless, studies have rarely focused on the experience and perspectives of medical teachers in flipped classroom of Korea.

Therefore, the purpose of this study was to explore the experience of medical teachers in the process of adapting flipped learning method through a phenomenological approach. Results of this study can provide useful information for medical teachers who want to design flipped class.

\section{Methods}

\section{Participants and data collection}

Participants were purposely recruited by authors. Four medical teachers from two medical colleges and one medical teacher from medical school were purposely recruited. They have been running flipped learning over 2 years in medical colleges (Table 1). The authors created a semi-structured interview guide with preponderance of open-ended questions to collect their experiences of flipped learning. The interview process

\begin{tabular}{cllll}
\hline Table 1. Basic & Data of Participants & & \\
\hline Participants & Age $(y r) /$ sex & \multicolumn{1}{c}{ Position } & Student year & \multicolumn{1}{c}{ Subject (class hours in 2017) } \\
\hline A & $48 / \mathrm{M}$ & Associate professor & Second & Reproductive medicine, nephrology (3 hr) \\
B & $51 / \mathrm{M}$ & Professor & Second & Clinical infectious diseases (11 hr) \\
C & $47 / \mathrm{M}$ & Associate professor & Second & Clinical reproductive medicine $(4 \mathrm{hr})$ obstetrics \& gynecology (11 hr) \\
D & $51 / \mathrm{M}$ & Professor & Second & Endocrine system \& nutrition $(3 \mathrm{hr})$ \\
E & $50 / \mathrm{F}$ & Associate professor & Second & Reproductive system (6 hr) \\
\hline
\end{tabular}

A belong to medical school as post-baccalaureate program. B, C, D, and E belong to medical college as undergraduate program.

M: Male, F: Female. 
was guided by designed questions as follows: (1) What were motivations for flipped learning?; (2) How did you do flipped learning?: prerequisite learning, class activities, and formative and summative assessment; (3) What did you experience with flipped learning?: and (4) What were the difficulties in flipped learning?

Interview was conducted in December, 2017. Each author conducted face-to-face in-depth interview with participant who was colleague at the same medical college or school after obtaining informed consent. The interview lasted about 60 minutes. All interviews were recorded. After finishing the interview, the authors transferred their own interview into electronic form using EXCEL 2016 (Microsoft Corporation, Redmond, USA) and assigned a sequential number to each interview. When additional data were needed, data were collected by telephone or email.

\section{Data analysis}

For data analysis, the seven-step approach suggested by Colaizzi [10] was applied as a phenomenological method (Table 2).

\section{Results}

We extracted a total of 160 unique significant statements. These statements generated 17 formulated meanings that were categorized into seven theme clusters and four theme categories (Table 3).

\section{Teacher characteristics: teachers with high levels of passion and motivation}

\section{1) Boredom with lecture-style classes}

Participants had doubt toward lecture-style classes when students perceived their classes to be uninteresting or boring and when they asked students what they had learned in class when they entered practicum. Moreover, they added that students' poor attitude was another cause. They wanted students to participate and learn more instead of them providing a unidirectional lecture. However, lecture-style classes presented limitations.

\begin{abstract}
"One thing that I was always pondering was, even if I raise my voice, some would sleep and others would chitchat $-\mathrm{I}$ tell them that they need to answer for me to proceed to the next slide, and the fact that I ask the
\end{abstract}

Table 2. The Seven-Step in a Phenomenological Approach

\begin{tabular}{|c|c|}
\hline Step & Descriptions \\
\hline 1. Reading and familiarization & $\begin{array}{l}\text { The authors read all transcribed interview frequently to familiarize with the data, and to arrive } \\
\text { at a clear understanding about the intended participant's experiences. }\end{array}$ \\
\hline 2. Extracting significant statements & $\begin{array}{l}\text { Significant flipped learning experiences-related statements were extracted and labeled with } \\
\text { formalized meanings. }\end{array}$ \\
\hline 3. Formulating meanings & $\begin{array}{l}\text { Meanings relevant to the phenomenon that arises from a careful consideration of the significant } \\
\text { statements were identified. The authors reflexively bracket pre-suppositions to stick closely } \\
\text { to the phenomenon as experienced. }\end{array}$ \\
\hline 4. Clustering themes & $\begin{array}{l}\text { The identified meanings clustered into themes that are common across all accounts. Pre-suppositions } \\
\text { were again bracketed when necessary. Thereafter, formalized meanings with similar connotations } \\
\text { were grouped into themes. }\end{array}$ \\
\hline 5. Creating an exhaustive description & A full and inclusive descriptions of the phenomenon were written, incorporating all the themes. \\
\hline 6. Producing the fundamental structure & $\begin{array}{l}\text { The authors condenses the exhaustive description down to a short, dense statement that captures } \\
\text { just those aspects deemed to be essential to the structure of the phenomenon. }\end{array}$ \\
\hline 7. Verification & The findings were referred to the participants to validate them. \\
\hline
\end{tabular}


Table 3. Schematic Process in Phenomenological Reduction

\begin{tabular}{|c|c|c|}
\hline Theme categories & Theme clusters & Formulated meaning \\
\hline $\begin{array}{l}\text { Teacher } \\
\text { characteristics }\end{array}$ & $\begin{array}{l}\text { Teachers with high } \\
\text { levels of passion } \\
\text { and motivation }\end{array}$ & $\begin{array}{l}\text { Boredom with lecture-style classes } \\
\text { Continuously studied new teaching methods: self-taught } \\
\text { Highly desire a teaching method that communicates with the students } \\
\text { Not afraid of failure }\end{array}$ \\
\hline $\begin{array}{l}\text { Hurdles of flipped } \\
\text { learning }\end{array}$ & $\begin{array}{l}\text { Students who } \\
\text { were still passive }\end{array}$ & $\begin{array}{l}\text { Students who do not prepare for lecture materials } \\
\text { Students who do not participate in questions and discussions: difficult to lead class due to lack } \\
\text { of active participation }\end{array}$ \\
\hline & $\begin{array}{r}\text { Struggling } \\
\text { teachers }\end{array}$ & $\begin{array}{l}\text { Difficulties in preparing videos: production, scripting, school support and familiarity } \\
\text { Difficulties in classroom preparation: case questions, quizzes, team-based learning, creating the } \\
\text { classroom environment }\end{array}$ \\
\hline $\begin{array}{l}\text { Positive changes } \\
\text { from flipped } \\
\text { learning }\end{array}$ & $\begin{array}{l}\text { Changes to the } \\
\text { classroom } \\
\text { environment }\end{array}$ & $\begin{array}{l}\text { No dozing students } \\
\text { Duration of self-directed learning increases (and lecture time decreases) } \\
\text { Develop the potential of students: students actively participating in discussions } \\
\text { Teacher with reformed roles of accelerator, fun-enabler and a guide } \\
\text { Searching for a more effective way of flipped learning }\end{array}$ \\
\hline $\begin{array}{l}\text { Challenges of } \\
\text { flipped learning }\end{array}$ & $\begin{array}{l}\text { Remaining tasks } \\
\text { for teachers } \\
\text { Expansion of } \\
\text { flipped learning }\end{array}$ & $\begin{array}{l}\text { Inducing student participation } \\
\text { Pondering on the appropriate evaluation method for flipped learning } \\
\text { Hope for other teachers to participate } \\
\text { School-level support }\end{array}$ \\
\hline
\end{tabular}

students to follow, only a few complied. Leading these classes with slides provided limitations for me to have deep conversations with my students given the classroom style." (Participant A)

\section{2) Continuously studied new teaching methods}

Participants felt limitations of lecture-style classes and reported that they attempted various class styles to raise student participation and learning efficiency such as tutor-less problem-based learning, team-based learning (TBL), and case-based learning during clinical training. They came across flipped learning by chance and they studied the concept and method of flipped learning through thesis papers, television media, and internet data.

"I haven't been to workshops or anything. I read a few papers, journals on medical education, and sometimes television some documentary about future learning series of KBS had a part with flipped learning with middle and high school students. They would be from high schools and sometimes universities in the United States. Also watched YouTube." (Participant C)

\section{3) Highly desire a teaching method that com- municates with students}

As participants felt limitations of lecture-based classes, they had the passion to try new teaching methods. They wanted to communicate with their students.

\footnotetext{
"Whenever I'm in class, I would throw out questions to students and when they don't answer, I would say, 'Hey, you need to answer to proceed to the next phase- if not, our hour-long class may be stuck on this bit and we will not be able to proceed with the other stuff. Please participate.' I led classes like that." (Participant A)
}

\section{4) Not afraid of failure}

All participants were not afraid of trial and error when they were attempting a new class style. They tried out diverse styles to raise learning efficiency and drive 
student participation. This kind of passion as teachers resulted in a comprehensive set of methodologies through trial and error while engaging in flipped learning.

\section{Hurdles of flipped learning}

\section{1) Students who were still passive}

a) Students who do not prepare for lecture materials Participants reported that it was effective to prepare for flipped learning using videos. However, there were students who would not watch them even if they were provided.

"If they agreed to view the videos in advance (in preparation), they need to see them; however, there are some students who come without watching, and we research who watched and who did not." (Participant C)

b) Students who do not participate in questions and discussions: difficult to lead class due to lack of active participation

As students were accustomed to lecture-based classes, it was difficult for them to voluntarily discuss and question in flipped learning classes. As such, they had to pick out students to answer.

"It's not like there were similar classes before, but since there are very little discussion-based classes, it is difficult to get them to voluntarily participate in discussion. When I call out their name, they reluctantly answer, and those who throw out questions are usually ones with good grades." (Participant B)

\section{2) Struggling teachers}

a) Difficulties in preparing videos: production, scripting, school support, and familiarity

All participants indicated that videos were the most effective way of preparing for class. When reading materials were given out for preparation, it was difficult to confirm if students had properly prepared in advance. If they did not prepare, discussions were almost impossible. They also indicated that it was difficult to produce these preparation videos because these videos took a long time. They were also technologically challenging. In addition, scriptwriting was difficult. Moreover, there was no school support. On the other hand, two participants who received support from the school to produce videos did not indicate difficulties in video production.

b) Difficulties in classroom preparation: case questions, quizzes, TBL, creating the classroom environment

They were also concerned about what student activities should be as much as they were concerned about video production. All participants formed their classes with activities that they had developed. These attempts were diverse. Sometimes case questions would be predeveloped by students and refined by teachers. Sometimes questions would be prepared by teachers alone. They also developed case studies that would be used in TBL.

"The most difficult part about flipped learning is to develop questions to be used in discussion classes. I typically prepare 10 questions, but developing the questions is the most difficult part. When I first started, it was hard and no one was around to teach me; but after 3 years, it's becoming easier." (Participant E)

"In my case, it took me about 6 hours to qualify the 20 questions from the students and organize it into a PowerPoint. Definitely not easy. It was my first time spending 6 hours on case development preparing for a 2-hour class, and this kind of effort is needed. Including 
all of the video shooting time. Including all the time that went into uploading questions on the Socrative app, I think I put in about 8 hours to prepare for a 2 -hour class." (Participant A)

\section{Positive changes from flipped learning}

\section{1) Changes to the classroom environment}

a) No dozing students

Participants indicated that the biggest advantage of flipped learning was the lack of students dozing off. As they needed to participate during class, students liked it as they did not feel sleepy during class. Group members needed to talk to each other in TBL. They needed to engage in discussion and question in case-based learning led by the teacher, resulting in no students dozing off.

"My students study on their own and deliver great presentations. When I delivered these classes in lectures, there were a bunch of students sleeping and they did not look motivated, but this method, it's completely different. They need to talk amongst themselves. I plan on continuing with this method next year. I highly recommend it to my colleagues." (Participant E)

b) Duration of self-directed learning increases

Participants reported that there were no cases of voluntary preparation for lecture-based classes. They indicated that prepared videos could be watched over again prior to the exam if there were anything that students did not know. Moreover, students were also satisfied as the duration of lectures decreased and they learned to study on their own. As this enabled repetitive learning, participants thought that this might have deepened the knowledge of students.

"The students learn how to develop questions and learn how to solve these questions, and they provide commentary, which is impossible if they do not have a sufficient understanding. The students deepen their understanding of the subjects." (Participant A)

c) Develop the potential of students: students actively participating in discussions

While there were students who often did not engage in preparation or remained passive during class, there were also students who actively participated and provided stellar explanations. Participants were satisfied when students were above expectations.

"I thought that shortening a 2-hour lecture into 20 minutes would be a disaster; shooting important parts on video and placing the remaining contents on the exam to discuss and study together has been very effective. I tried four cases of TBL. The students are great, and their level of achievement is very high. You'll be surprised with my students." (Participant E)

\section{2) Reflection through experience}

a) Teacher with reformed roles of accelerator, funenabler, and a guide

Although these teachers were originally involved in providing information, they reported that having accelerated classroom participation enabled fun.

"I put on the stopwatch when the students started solving problems. I tell them to start their group discussion. Once the alarm goes off, I turn it off and tell them to write the answer down and hand it in. When there is a team with a different answer, I get the teams with wrong answers to explain why their answer was thus. I'm a guide." (Participant A)

"As they all have notepads and notebooks, they write the 
Kyung Hye Park, et al: Experiences of medical teachers in flipped learning

answers on them and hold them up. I enable fun, for example, I would say 'applause!' if everyone gets the answers right." (Participant A)

b) Searching for a more effective way of flipped learning

Participants who operated the same class using the flipped learning method for over 2 years modified the second flipped learning experience to enable students to participate. They changed their reading materials into videos, developed new cases every year, changed teacher-led discussion to TBL, and attempted methods to improve student participation.

\section{Challenges of flipped learning}

\section{1) Remaining tasks for teachers}

a) Inducing student participation

Participants wanted more active interactions with students. They thought that they did not achieve perfect student participation as teachers were ultimately leading the discussion.

\footnotetext{
"I'm disappointed that I was not able to interact with the students in an active manner. The students vote using cricket but they would have felt something or thought something at that moment... this I would miss. The interaction would be picking out a few students and asking them why they had responded thus, and compared to before, it was the same as me completely controlling the class. While student participation rose significantly, it was not flipped learning in its true meaning." (Participant D)
}

b) Pondering on the appropriate evaluation method for flipped learning

While class style changed to satisfaction, participants were disappointed in evaluation as it remained the same.
"I think perfection would be achieved when compared with an appropriate evaluation tool. However, I'm carrying out flipped learning and the present evaluation tool is still the same multiple choice. We need to think more about what is the most appropriate evaluation tool for flipped learning." (Participant A)

\section{2) Expansion of flipped learning}

a) Hope for other teachers to participate

All participants engaged in flipped learning on classes they taught in the medical school. One participant who was the teacher in charge had recommended flipped learning to other teachers. However, he stopped such recommendation after he did not see much success. Moreover, other participants indicated that flipped learning should be at least half of the entire curriculum to change student tendencies to study voluntarily and wanted to share their flipped learning experience. However, for multiple teachers to engage in flipped learning, it was necessary for them to engage in new but simple attempts such as quiz apps.

\section{b) School-level support}

Participants operated flipped learning classes after discovering its necessity by themselves and undergoing multiple trials and errors. Therefore, they underscored the need for school-level support. At the preparation stage, they required technical support such as an opportunity to learn about flipped learning and video production know-how. A teacher using TBL in their class underscored the need for personnel support as it was very difficult to operate the entire class by themselves.

"I'm collecting answer sheets and leading the class, it's very difficult to do it by myself. Even if there is a teaching assistant, conducting a whole class by oneself is very hard without a significant level of passion or 
interest. My entire focus, after one class, my focus evaporates. There are much to be prepared in advance, especially if the base was to be expanded to other teachers, like those coaching beside you, like list of things to prepare... it's possible with one teaching assistant. But based on my experience, it's very difficult." (Participant C)

\section{Discussion}

Flipped learning is in the spotlight these days as a new teaching and learning method. Studies are also being actively conducted on its effects. These studies are about the benefits and usefulness of flipped learning. Most of these studies are focused on the 'learner' [11-13]. However, there are not many studies on characteristics of 'teachers' who prepare for and conduct classes, especially difficulties or perceptions they experience in the process of flipped learning. Thus, the present study explored the experiences of five medical teachers at three medical schools regarding the process of adapting to flipped learning method through a phenomenological approach.

In the interview, the researchers were able to categorize these medical teachers' experiences about flipped learning into four categories. The first category was character of the medical teacher. Medical teachers had a high incentive to teach with enthusiasm for education. These teachers were thinking about what it was like to teach medical school students well, why they should teach them this way, and how to teach them better. They studied flipped learning for a better understanding of education and reflected on how to involve their students in the thought process.

The second category was difficulties in flipped learning. These medical teachers had difficulties with passive students about new learning methods and unfamiliar teaching methods. These difficulties involved 'activities in the classroom'. Flipped learning requires a more dynamic and flexible learning environment compared to lecture with the traditional instruction approach. Both medical teachers and students must undergo a change in their perception of learning culture in order to achieve successful flipped learning. In particular, even if there is not much activity of medical teachers in the class time, the influence of medical teachers required in the course of the class will have a considerable effect on students. Thus, pedagogical considerations of expertise are required for medical teachers.

The third category was positive change that flipped learning brought. These medical teachers could feel changes not only for students, but also for medical teachers themselves through flipped learning. Flipped learning turned passive students in the lecture oriented classroom into active learners. Flipped learning plays the most important role in creating opportunities for interactions between the teacher and the student as well as among students. Consequently, medical teachers should pay attention to how to facilitate the study of individualized learning in his/her flipped learning.

The fourth category was challenge for flipped learning. These medical teachers indicated that administrative and institutional support for the class was a challenge of flipped learning. These teachers must produce video before class and must constantly monitor activities in the classroom to apply student-oriented teaching methods. To spread the flipped learning method in medical schools, it is necessary to find ways to effectively carry out flipped learning while reducing the burden on medical teachers to prepare and execute the instruction.

This study has some limitations. First, only five medical teachers in three educational institution were 
enrolled for this study. Such small number of medical teachers who participated in this study might not have much flipped learning's experiences. Thus, future studies should include a wide range of medical teachers.

In conclusion, the present study placed stress on elucidating categories utilizing a qualitative approach to explore the experience of medical teachers in the process of attempting flipped learning as a new method of teaching. Through phenomenological approach, we were able to hear a variety of authentic examples of medical teachers regarding the process of adapting flipped learning. Although these medical teachers who participated in the study did not have the same ideas on how flipped learning was conducted and implemented, their perception of flipped learning, or difficulties they faced in class activities, they all wondered how they could teach students well. Results of this study might draw more attention to flipped learning and stimulate educational and institutional supports to improve teaching and learning in medical schools.

\section{ORCID:}

Kyung Hye Park: https://orcid.org/0000-0002-5901-6088; Kwi Hwa Park: https://orcid.org/0000-0002-0008-2400; Su Jin Chae: https://orcid.org/0000-0003-3060-8933

Acknowledgements: None.

Funding: None.

Conflicts of interest: No potential conflict of interest relevant to this article was reported.

Author contributions: Conception or design of the work: KHP2; data collection, data analysis and interpretation: KHP1, KHP2, SJC; drafting the article: KHP1; critical revision of the article: SJC; and final approval of the version to be published: KHP1, KHP2, SJC.

\section{References}

1. Prober CG, Heath C. Lecture halls without lectures: a proposal for medical education. $\mathrm{N}$ Engl J Med. 2012;366(18):1657-1659.

2. Lage MJ, Platt GJ, Treglia M. Inverting the classroom: a gateway to creating an inclusive learning environment. J Econ Educ. 2000;31(1):30-43.

3. Street SE, Gilliland KO, McNeil C, Royal K. The flipped classroom improved medical student performance and satisfaction in a pre-clinical physiology course. Med Sci Educ. 2015;25(1):35-43.

4. Chen F, Lui AM, Martinelli SM. A systematic review of the effectiveness of flipped classrooms in medical education. Med Educ. 2017;51(6):585-597.

5. Bouwmeester RA, de Kleijn RA, ten Cate OT, van Rijen HV, Westerveld HE. How do medical students prepare for flipped classrooms? Med Sci Educ. 2016;26(1):53-60.

6. Sharma N, Lau CS, Doherty I, Harbutt D. How we flipped the medical classroom. Med Teach. 2015;37(4): 327-330.

7. Hermanns M, Post JL, Deal B. Faculty experience of flipping the classroom: lessons learned. J Nurs Educ Pract. 2015;5(10):79-85.

8. Shin YJ, Ha JH, Lee SH. An analysis of the perceptions and difficulties experienced by science teachers in flipped learning. J Korean Assoc Sci Educ. 2016;36(1):159-166.

9. Si JH. Effects of flipped learning on approaches to learning of medical students. Korean J Educ Methodol Stud. 2017;29(2):347-370.

10. Colaizzi PF. Psychological research as the phenomenologist views it. In: Valle RS, Kings M, eds. ExistentialPhenomenological Alternative for Psychology. New York, USA: Oxford University Press; 1978:48-71.

11. Lee JY, Kim YH, Kim YB. A study on application of learner-centered flipped learning model. J Educ Technol. 
2014;30(2):163-191.

12. Kim R, Song HD. University-level flipped classroom learner competency modeling. J Educ Technol. 2017; 33(4):1001-1024.
13. McLaughlin JE, Roth MT, Glatt DM, et al. The flipped classroom: a course redesign to foster learning and engagement in a health professions school. Acad Med. 2014;89(2):236-243. 